\title{
Heriberto Frías y la versión pedagógico-literaria de la conspiración del marqués del Valle
}

\author{
Eduardo Ayala Tafoya \\ Facultad de Filosofía y Letras. UNAM \\ tafoyita@hotmail.com
}

\begin{abstract}
Resumen: Durante el Porfiriato, la reforma a la educación primaria prestó especial atención a la enseñanza de la historia y también a la literatura de apoyo para impartirla. En este contexto, Heriberto Frías (1870-1925) escribió una colección titulada "Biblioteca del Niño Mexicano" que - fuertemente impregnada de la visión liberal — recrea diferentes episodios de la historia patria para forjar en los educandos un sentimiento de identidad nacional. El presente estudio analiza las referidas cargas ideológicas en uno de dichos opúsculos: La conspiración del marqués del Valle.
\end{abstract}

Palabras Clave: Heriberto Frías; Biblioteca del Niño Mexicano; Liberalismo; Literatura pedagógica.

Авsтract: The Porfirian era conducted an educational reform in elementary school in which History was to play a leading role, and books were needed to support the teaching. Heriberto Frías (1870-1925) wrote a collection of history books for children entitled "Biblioteca del Niño Mexicano". Strongly inspired by liberal principles, the books dealt with important historical events in Mexico and intended to create a sense of national identity among the students. The present study discusses the highly ideological baggage in one of such books: $L a$ conspiración del marqués del Valle.

Keywords: Heriberto Frías; Biblioteca del Niño Mexicano; Liberalism; Pedagogical literature.

FECHA DE RECEPCIÓn: 27 de agosto de 2015

FECHA DE ACEPTACIÓN: 26 de noviembre de 2015

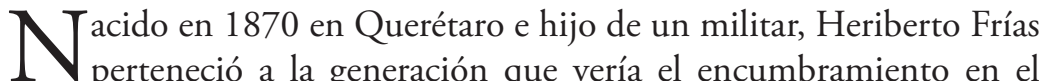
poder de Porfirio Díaz y el ulterior desarrollo de la Revolución que lo derrocó. La vida de Frías casi siempre estuvo marcada por un signo trágico: la temprana muerte de su padre lo obligó a dejar sus estudios en la Escuela Nacional Preparatoria y a ganarse el sustento con los humildes empleos que se le ofrecieran. Anémico y aquejado de afecciones 
oculares, hubo de abandonar la escuela y en razón de haber hurtado luego una pequeña cantidad a su patrón, se le sentenció a pasar ocho meses en la cárcel de Belén. Ahí se aficionó a la marihuana, a las apuestas y a los demás vicios comunes de los presidiarios (sobre la vida de Frías, cfr. Brown: 17-19; García: 14-15). Y si su destino no fue peor, se debió únicamente a que su mayor nivel educativo respecto de los demás internos le permitió ganarse su respeto escribiendo cartas y versos por encargo.

No obstante, estas experiencias tempranas en las calles de la capital y en sus prisiones - pues no sería ésta la única vez que pisaría tales recintos - moldearían su pensamiento y le harían tomar el partido de los pobres, los marginales y los oprimidos (García: 16-17).

Luego de su liberación, Frías tomó otro trabajo modesto, mientras leía y estudiaba por su cuenta. Así hubiera continuado pero, a finales de 1887, un viejo amigo de su padre le ayudó a ingresar al Colegio Militar. Su constitución débil, su vista corta y su timidez lo hacían víctima de las burlas de sus compañeros. Aun así, por solidaridad, quiso un día interceder en favor de algunos de ellos que recibían un castigo; el resultado fue que la pena le fue aplicada sólo a él y que oficiales y condiscípulos lo aislaron aún más que antes.

Sin embargo, a raíz de estas experiencias, sus ideas políticas y sociales se fueron perfilando mejor; su empatía con los pobres y excluidos, su aversión a los poderosos deben mucho a la infelicidad que lo acompañó en las calles y en la vida de cadete (Brown: 20). Definiéndose como un "librepensador", terminó por unirse a los discípulos de don Guillermo Prieto, que a la sazón era su profesor de historia y que tenía fama de "jacobino rojo" (véase infra: "Proyectos pedagógicos liberales y positivistas. Los debates"). Con él debe haberse iniciado su inclinación por el saber histórico.

A un año de su ingreso al Colegio Militar, esto es en 1889, dejó la academia y se enroló en el ejército como subteniente en el noveno batallón de infantería. Pero en la institución castrense no le fue mejor: repetidas veces fue recluido en la cárcel militar de Santiago Tlatelolco, acusado de indisciplina, mala conducta y embriaguez; además, su gusto por las mujeres le dejó una sífilis que requirió hospitalización. Aun así, Frías alentaba sueños de gloria bélica (Brown: 21; García: 41).

En octubre de 1892, su batallón fue enviado a Chihuahua, a combatir la rebelión de los habitantes de Tomóchic. El pequeño pueblo fue aniquilado y destruido por los soldados. Obligado por su condición 
militar a cometer actos de barbarie contra unos indígenas a los que respetaba y compadecía, Frías fue simultáneamente testigo, victimario y víctima en un breve episodio de sangre que lo horrorizó, por mucho que, al final, lo hubieran ascendido al rango de teniente (Brown: 22).

Leyendo en un diario la distorsionada versión de los hechos de la recién finalizada campaña de Tomóchic, se animó a escribir, en sólo una semana, un detallado relato de sus experiencias que luego remitió a Joaquín Clausell, editor de un periódico de oposición al porfirismo, El Demócrata. La respuesta del editor fue una entusiasta nota, que informaba al joven teniente que su texto se publicaría como novela por entregas (Brown: 23-24).

Tomóchic causó gran revuelo en la opinión pública, profunda indignación en los altos mandos del ejército y un arrebato de cólera a don Porfirio. Aunque publicada anónimamente, se rumoraba el nombre del autor, a quien expeditamente se le abrió un consejo de guerra por divulgar asuntos de campaña (García: 22-23; Brown: 25-26). Frías fue degradado y dado de baja de las fuerzas armadas por instrucciones presidenciales y si no se le condenó a la pena capital fue sólo para ahorrarse mártires que la oposición política pudiera capitalizar. Como fuese, el primer éxito editorial de Heriberto Frías volvió a ponerlo en la calle y en la tesitura de seguir buscándose la vida en un medio adverso (García: 24). ${ }^{1}$

En los años inmediatos Frías trabajó en periódicos de poca monta, aunque este hecho no lo disuadía de llegar a unirse alguna vez a lo que imaginaba como una hermandad de periodistas cuyas banderas eran la verdad y la justicia (Brown: 27). A sus 25 años volvió a darse a la francachela, al alcohol y a la morfina, y en consecuencia perdió buenas oportunidades laborales. En 1895 regresó a las celdas de Belén, esta vez como apoyo a su amigo y colega José Ferrel, encarcelado por "difamación”. En su nueva estancia carcelaria terminó su segunda novela, Los naufragios, posteriormente reescrita y rebautizada El amor de las sirenas. En prisión escribió también El último duelo (Brown: 28-29; García: 17).

Durante los siguientes ańos produjo muchos artículos y novelas, entre ellos Leyenditas históricas y Leyendas históricas, que más tarde apare-

${ }^{1}$ En Tomóchic, y en otras obras posteriores, se percibe la influencia de la literatura de protesta social de Émile Zola. Más información al respecto en López y Saborit. 
cieron en El Imparcial. A partir de 1899 la Casa Maucci ${ }^{2}$ (Martin 2006) le publicó una larga serie de folletines titulada "Biblioteca del Niño Mexicano" que, aunque escritos apresuradamente, le proporcionaron medios para subsistir con estrecheces. También por estos años publicó sus Episodios militares mexicanos (1901), que plasman su respeto por los soldados del ejército nacional (Brown: 30; García: 41-42).

En 1906 se trasladó a Mazatlán para hacerse cargo del periódico más longevo y mejor reputado del occidente de México, el Correo de la Tarde. Tres años después participó en la campaña política de su viejo amigo José Ferrel en Sinaloa. Pero Ferrel perdió ante el candidato porfirista y, dada la persecución, Frías se vio obligado a regresar a la Ciudad de México. Más tarde devino maderista y se afilió al partido Antirreeleccionista; a petición de Madero se hizo cargo del recién fundado periódico El Constitucional. El apoyo al coahuilense le valió para acceder al comité central del partido vencedor y, más tarde, lo elevó al puesto de subsecretario de Relaciones Exteriores. Tras el golpe de Estado de Victoriano Huerta se unió a los revolucionarios que lo combatían en la frontera norte. Una vez reunida la Convención de Aguascalientes, Frías participó en las acaloradas sesiones como miembro y periodista de $L a$ Convención y El Monitor. En el enfrentamiento entre convencionistas y carrancistas, don Heriberto se alió con los primeros y criticó incisivamente a Carranza en los periódicos que dirigía. Cuando éste triunfó, Frías cayó en desgracia; fue acusado de rebelión y compareció ante un consejo de guerra que lo sentenció a muerte, pese a la activa defensa de periodistas y amigos. Finalmente, Carranza le conmutó la pena por ocho meses de prisión.

Durante el gobierno de Álvaro Obregón, recuperó su posición y fue nombrado cónsul de México en Cádiz, cargo que desempeñó de 1921 a 1923, tiempo durante el cual también escribió su última novela, ¿Águila o sol? Murió en la Ciudad de México en 1925 a los 55 años de edad y completamente ciego (Antuñano: 15-18). ${ }^{3}$

La vocación de escritor en Frías fue diversa y transitó por varios géneros: el periodismo, la historia, la novela, el cuento, la leyenda, la viñeta,

${ }^{2}$ Propiedad del italiano Emmanuele Maucci y sus hermanos. La casa matriz fue fundada en Buenos Aires en 1872; poco después dos de los hermanos Maucci, Carlo y Alessandro, se trasladaron a México para establecer otra filial.

${ }^{3}$ Este mismo autor ofrece una detallada bibliografía de sus diversas obras en las páginas 31-35. 
el teatro y la poesía. A la "Biblioteca del Niño Mexicano" le imprimió su particular visión de la historia de México, imbuida de un romanticismo liberal decimonónico que pintaba héroes y villanos, buenos y malos. En palabras de Frías "el verdadero periodista futuro será el maestro del pueblo, crítico, el divulgador, jel iluminador! Y nosotros, los peones del periodismo, los reporteros, seremos los historiógrafos, y hasta los novelistas y romanceros [y con nuestro] verbo informativo, documento histórico, aplaudiremos a los futuros maestros y organizadores" que representen la verdadera tradición moral del pueblo mexicano a través de su historia (Frías: 165, 167; García: 46-47; Antuñano: 19).

\section{Proyectos PedagóGicos liberales y Positivistas. Los Debates}

Durante gran parte del siglo XIX, México padeció la prolongada lucha por la hegemonía política entre los bandos conservador y liberal. Junto con el poder, se peleaba igualmente la implantación de una visión histórica nacional que, mirando al pasado, forjara proyectos políticos para el futuro del país. El nacionalismo conservador cargaba "toda su nostalgia hispánica, su pesimismo, su antiyanquismo obsesivo"; en tanto que el liberal se ostentaba "antiespañol, antiyanqui, antifrancés por algún tiempo, y con una medida de nostalgia indigenista, pesimista y defensiva" (Vázquez: 68; Escandón: 33).

Aun con estas discrepancias, liberales y conservadores compartían la apremiante preocupación de buscar y consolidar los valores y símbolos de la conciencia e identidad nacionales y la obligación de heredar y difundir dicho conocimiento a las siguientes generaciones de ciudadanos mexicanos. Naturalmente, unos y otros se ostentaban como custodios exclusivos de la verdad y la justicia históricas de la nación y todos consideraban que la mejor manera de divulgar sus respectivas posturas y ganar adeptos para ellas era la educación escolar; empero, tras el fin de la Guerra de Reforma, el triunfo liberal permitió a esta facción plantear un proyecto de instrucción pública que consolidara su ideario (Escandón: 33).

Así, en 1859 se dispuso la obligatoriedad de la instrucción elemental, cuyo programa incluía la enseñanza de la historia patria. Algunos años después se creó la Escuela Nacional Preparatoria (1867); en su plan de estudios también se consideraba a la historia, pero supeditada al orden lógico de los conocimientos científicos del positivismo de su fundador, 
Gabino Barreda. Los alcances y efectos de la educación básica fueron muy limitados: la mala situación económica del país, la ausencia de programas a escala nacional, la carencia de una planta docente formal y otras diversas circunstancias impidieron su éxito. Mejor suerte corrió la Escuela Nacional Preparatoria, que llegó ya afianzada a la etapa porfirista. El caudillo de alguna manera le prodigaba un elogio al decir que "si todos los mexicanos aprenden lo mismo tenderán a actuar de la misma manera", es decir, ordenadamente. La Preparatoria impartía un fondo común de verdades (mediante el "amor, orden y progreso"), indispensable para el orden intelectual que, a su vez, era la base de todo orden social y moral (Bazant 2006: 159). ${ }^{4} \mathrm{El}$ ansiado progreso de la era porfiriana era la señal más visible de que México comenzaba a sacudirse su pasado "bárbaro", y los paulatinos avances hacían creer que por fin el país podría convertirse en el artífice de su propio destino (Bazant 2006: 15).

Frente a la heterogeneidad cultural y étnica, el gobierno de Díaz asumía - como ya antes la generación de liberales de Benito Juárezque la única forma de conferirle unidad a México era a través de una instrucción elemental obligatoria, laica y uniforme que erradicara el analfabetismo y la "anarquía mental" endémicas de antańo (Bazant 2006: 16-17; Bazant 1985: 9). ${ }^{5}$

Con miras a alcanzar tales objetivos, Joaquín Baranda, ministro de Justicia e Instrucción Pública, lanzó una convocatoria para la celebración de congresos de instrucción pública; así, los de 1889 y 1890 fijaron lineamientos y marcaron los derroteros que las políticas educativas

${ }^{4}$ La influencia de la ENP a nivel nacional indujo a que otros estados adoptaran, para sus propios institutos científicos y literatos, en ocasiones con reservas, el plan de estudios positivista.

${ }^{5}$ Esta autora ha analizado los alcances del proyecto educativo porfiriano y ha sostenido el aumento del índice de nińos que asistía a la escuela, pero no el del alfabetismo. Donde sí se dio un aumento fue en los debates e ideologías, que fueron el medio de introducir la modernidad en la educación. Más allá de esto, también existían varios obstáculos que debían enfrentar los encargados de llevar a la práctica las más novedosas teorías educativas. En esta época México tenía una población eminentemente rural frente a una minúscula que vivía en ciudades. Por tanto, la labor de educar de forma masiva a toda la población era titánica sin los suficientes medios (falta de vías de comunicación, heterogeneidad de etnias y lenguas, escasez de recursos estatales y municipales, prejuicios raciales —inferioridad del indio—- etc.). Empero, el desenvolvimiento del proyecto educativo porfiriano fue disímil, pese a ello la base de la educación actual se gestó durante estos años, que van de 1876 a 1910. 
debían seguir, o al menos esbozar, en los territorios y la capital del país (Bazant 1985: 9). ${ }^{6}$ Fundamentados en las premisas de la obligatoriedad, gratuidad y laicismo de la educación, plantearon el modelo de la "nueva escuela mexicana" que, buscando el desenvolvimiento armónico e integral de los educandos en los planos moral, físico, intelectual y estético, abjuraba de la vieja escolástica y del aprendizaje memorístico. En el nuevo proyecto, los textos pasaban a un plano secundario, en tanto que la figura del maestro se erigía como el vehículo más importante de transmisión de saberes, como impulsor del pensamiento y la crítica (Bazant 1985: 10-11; Bazant 2006: 19-30).

Un lugar importantísimo en la "nueva escuela" se asignaba a la identidad nacional, así que uno de sus cometidos era desarrollar en los escolares el amor a la patria y a sus instituciones. En este sentido, la enseñanza de la historia ascendió, por vez primera, a un elevado sitial (Bazant 2006: 24-25). El programa de la asignatura de historia patria introducía a los niños de primer año al conocimiento histórico a través de la vida de los grandes personajes del pasado mexicano; en el segundo, estos relatos biográficos eran ampliados por el maestro para proporcionar más detalles y "conversaciones familiares". El tercer año incluía una panorámica general sobre la historia antigua y la época colonial, y para el cuarto, se abordaban la Guerra de Independencia y la historia del México independiente hasta el momento de la intervención francesa. En quinto año se debía ampliar lo anteriormente visto, insistiendo en "los hechos que han ido cambiando la faz de nuestro país". Únicamente hasta el sexto ańo, tras haber reafirmado el carácter nacional, se introduciría al escolar en la historia general a fin de "despertar el amor a la familia humana" (Vázquez: 111-112).

$\mathrm{Al}$ término del primer congreso, varios pedagogos se reunieron con el fin de idear métodos de apoyo a la reforma escolar. Se vio la necesidad de crear, para las distintas materias, un conjunto de guías metodológicas serias y modernas, según los modelos de Europa; de ahí procedió el primer boom de literatura didáctica sobre la enseñanza de la historia patria. El connotado pedagogo suizo-mexicano Enrique Rébsamen es-

${ }^{6}$ En la medida en que la Constitución de 1857 era federalista, el ministerio no tenía facultades para imponer a los estados sus leyes educativas. Los congresos significaron entonces un buen medio de negociación para cimentar la base de una educación uniforme. 
cribió entonces una Guí metodológica para la enseñanza de la historia en las escuelas elementales primarias y superiores de la república (1891) (Vázquez: 112; Escandón: 40; Bazant 2006: 64). En su concepto, la escuela era la vía para forjar la unidad nacional y la enseñanza de la historia constituía "la piedra angular de la educación nacional [pues] junto con la instrucción cívica, forma al ciudadano" (Rébsamen: 5). Sin embargo, advertía que los maestros no debían ponerse jamás al servicio de ningún partido político, religioso o social, sino que estaban obligados a mantener la imparcialidad y la tolerancia. En otras palabras, no debían falsificar, adulterar ni sesgar la verdad de la historia, ni siquiera por patriotismo, a riesgo de corromper la buena fe de sus alumnos (Bazant 2006: 102-103).

La propuesta de Rébsamen no fue del agrado de todos, en principio porque provenía de un "extranjero". El 23 de enero de 1891 Guillermo Prieto comenzó a polemizar con él en una serie de artículos publicados en El Universal. Aunque compartía su postulado de que la escuela era el germen de toda la nación (el lugar donde se empieza a poner en práctica las funciones políticas y sociales de los educandos) (Vázquez: 113), tenía profundas diferencias con Rébsamen en cuanto a la metodología didáctica de la historia. Para Prieto no bastaba con hacer un relato verdadero de los hechos históricos, era también menester exponer los vicios y errores del "enemigo" (en este caso, el partido conservador), al tiempo que se difundían los principios del partido liberal, el del progreso. En consecuencia, era inevitable poner a los estudiantes en contacto con temas de política y religión (Vázquez: 113; Ortega: 283). ${ }^{7}$ Este afán "pedagógico" de Prieto — llamado "el Rojo" por su radicalismo-, seguramente era motivado por sus propias experiencias personales en las guerras de Reforma. En contrario, Rébsamen había llegado a México en 1884, cuando el país ya no estaba en lucha y cuando hacía más de dos décadas que se había entronizado definitivamente el liberalismo en el gobierno (Vázquez: 114).

El resto de esta controversia pedagógica ya no reviste mayor interés para el presente texto, pero sí importa subrayar lo fogoso de la postura de Prieto relativa a la enseñanza de la historia patria, porque ya se ha indicado que don Guillermo fue el maestro de historia de Heriberto

\footnotetext{
${ }^{7}$ Para quienes estén interesados, Ortega hace un detallado análisis de la polémica Prieto-Rébsamen.
} 
Frías en el Colegio Militar. Y es difícil que el joven Frías se hubiera sustraído al influjo de la combativa versión del pasado mexicano que el benemérito maestro enseñaba a sus alumnos. Por ello quiero también destacar dos rasgos del pensamiento del viejo liberal que, sin duda, se transmitieron al concepto histórico que se forjó Heriberto Frías y que inevitablemente trascendieron a su "Biblioteca del Niño Mexicano". El primero es que asumía que el vehículo idóneo para la enseñanza de la historia de México era una narración que deleitara y estimulara la imaginación infantil; el segundo, la importancia que concedía a la transmisión de una visión histórica consecuente con los principios "de igualdad y libertad en los que se asienta el liberalismo, lo que implica también una condena a la conquista, al mundo colonial, al fanatismo de los conservadores, a las prebendas y privilegios eclesiásticos" (Escandón: 41).

En lo primero no puede atribuirse originalidad alguna a Prieto, quien a pesar de su rechazo por el antiguo mundo hispánico, era deudor de la tradición ciceroniana presente en todas las crónicas e historias del periodo virreinal, que consideraba a la historia como maestra de vida y que prescribía el relato persuasivo y terso para acicatear con el ejemplo (Prieto: V). Tales preceptos tenían un añejo arraigo en estas tierras, sólo que en la vertiente liberal; los antiguos paradigmas de santidad cristiana eran reemplazados por la biografía de los próceres, pues, según argumentaba Prieto, "el niño conserva la imagen de ciertos personajes, se enamora de su carácter, admira sus altos hechos, se aflige con sus desgracias, se identifica con sus modelos y los menciona en sus juegos"; don Guillermo aconsejaba al maestro, igualmente, desarrollar bien sus habilidades oratorias y explicativas para mantener la atención de sus educandos, porque de ello dependía que éstos desarrollaran una "imaginación viva [y así] creerán ver y oír [a los grandes héroes de su patria]" (Ortega: 287, 288, 292, 293 y 294).

En cuanto a lo segundo, el parecer de Prieto era que en la escuela había de impartirse una "instrucción cívica" que se fundamentara en la enseñanza de los "grandes principios de libertad, de igualdad, de solidaridad fraternal que son razón de ser de las sociedades modernas... [y] que son hijos de la revolución". Sólo ellos harían posible el progreso y el bienestar de la patria, razón por la cual habría de hablarse a los niños de las "libertades sociales y políticas", de las "conquistas que elevan, reivindican y fortalecen la dignidad del hombre y su aptitud para llenar sus grandes destinos" (Ortega: 290, 296). En este sentido, naturalmente, 
habría que inducir a los educandos a renegar de aquel pasado que, mediante la Conquista, había introducido en el Nuevo Mundo el "atraso" de la civilización occidental. Porque aun la obra benéfica de la cristianización se había pervertido para propiciar la explotación de los pueblos indígenas (Escandón: 36). Tres siglos después, la "gloriosa revolución de 1810 " había traído consigo los "bienes y beneficios inmensos" de una nación independiente, pero aún era necesario estar alerta y combatir a los grupos de conservadores, partidarios "de la dominación española y de la monarquía, enemigos irreconciliables de la constitución [de 1857] y la Reforma, levadura inmunda de la traición y el retroceso de los intereses nacionales", porque tratan de reactivar o de mantener vivos los "horrores del fanatismo, lo despótico y cruel de las clases privilegiadas" (Ortega: 291, 295 y 297). Tal era el credo pedagógico de Guillermo Prieto en materia histórica y ése fue el guión que tomó por bueno su discípulo, Heriberto Frías. ${ }^{8}$

\section{La "Biblioteca del Niño MeXicano"}

Durante la segunda mitad del siglo xix y a partir de los esfuerzos de los liberales para elevar a rango constitucional a la educación elemental, la infancia cobró un inusitado protagonismo en la vida del país. De algún modo, en el imaginario colectivo, los nińos dejaron de ser adultos en miniatura y se transformaron en promesas de futuros ciudadanos de una república moderna, a los que era indispensable formar en las virtudes cívicas: algo que sólo podía transmitir la historia patria.

\footnotetext{
${ }^{8}$ Si bien Prieto se erigió como la influencia principal del joven Frías, no debe soslayarse que don Guillermo fue un insigne protagonista de su horizonte histórico-cultural. Primero, de la lucha entre conservadores y liberales y, segundo, del triunfo y puesta en práctica del proyecto ideológico de éstos. Asimismo, formó parte de una "tradición" de autores de la segunda mitad del siglo XIX interesados en construir a la nación desde distintos frentes: historia, literatura, geografía, música, etc. Prieto fue contemporáneo de una pléyade de intelectuales como Lucas Alamán, José María Luis Mora, Carlos María de Bustamante, Lorenzo Zavala, Manuel Orozco y Berra, Niceto de Zamacois, Manuel Payno, Francisco Zarco, Ignacio Manuel Altamirano, Vicente Riva Palacio, Antonio García Cubas, Juan A. Mateos, José T. de Cuéllar y muchos más. Por la obligada brevedad de este texto, y porque otros son sus fines, me es imposible profundizar en las obras de estos personajes. Para un análisis más profundo de esta generación véanse Pi-Suñer 1996, Fernández 2006 y Cortázar 2006.
} 
En este sentido, muchos intelectuales de la época, y entre ellos reputados historiadores, se quejaron de la carencia de libros de texto adecuados, principalmente de buenas síntesis de historia de México que, por una parte, se instituyeran como una guía adecuada para el maestro y, por la otra, sirvieran como un medio de refuerzo de aprendizaje para el alumno en los temas que se trataban en las lecciones o cátedras. Aunque en este rubro Justo Sierra había escrito ya algunos buenos libros, lo que generalmente había eran "catecismos históricos", textos que, en la modalidad de preguntas y respuestas, fomentaban el aprendizaje memorístico pero no la comprensión y que sólo servían para convencer a los estudiantes de la absoluta inutilidad del estudio de la historia. Lo que se echaba de menos eran obras que, en un bosquejo general y mediante una exposición sencilla y sucinta de conceptos básicos, ofrecieran los acontecimientos fundamentales de la historia patria, de acuerdo con la matriz ideológica del Estado liberal mexicano (Escandón: 34-35).

Con el ánimo de subsanar tales carencias —y como se ha señalado en otro lugar-, entre 1899 y 1901 la casa editorial Maucci Hermanos publicó una colección intitulada "Biblioteca del Niño Mexicano", obra de Heriberto Frías. Eran cinco series de cuadernos o folletines, con un total de 85 números de alrededor de 16 páginas cada uno, ilustrados con pequeños grabados a color. Cabe señalar que cuatro de las portadas de estos fascículos son grabados de José Guadalupe Posada, quien, se dice, también fue autor de más de cuatrocientos para los interiores. En esta colección, Frías refería leyendas, sucesos o biografías noveladas de la historia nacional que iban desde el remoto pasado prehispánico hasta los acontecimientos del 5 de mayo de 1862 (Antuñano: 39-52). ${ }^{9} \mathrm{Y}$ en la medida en que su propósito era la divulgación histórica, los títulos denotan claramente la intención de seducir a un público de menores que gustaba de las hazañas y los enigmas: $L a$ princesa Rayo de Gloria y la fundación de México, El fantasma carnicero o el pavor de los verdugos, El caballero misterioso y el capitán conquistador o la batalla de Centla, Aventuras del principe Flor de Nopal o la gratitud de un amigo, etcétera.

Junto a otras ediciones coetáneas de factura similar (Antuñano: 2425), ${ }^{10}$ la "Biblioteca del Niño Mexicano" fue precursora, en el país, del

\footnotetext{
${ }^{9}$ La secuencia completa y los títulos de cada folletín las señala este autor.

${ }^{10}$ Este autor menciona las restantes obras.
} 
relato corto de la literatura infantil que difundía, en un lenguaje accesible, episodios y personajes de la extensa historia de la nación mexicana. En cierta forma, por una parte, y en lo que toca a los elementos de ficción literaria, la colección de Frías constituye una reminiscencia "en escala menuda" de los Episodios nacionales de Benito Pérez Galdós (publicados en España a partir de 1873 y que serían la inspiración para los de Victoriano Salado Álvarez en México a partir de 1902) (Brown: 50). ${ }^{11}$ Por la otra, y en razón de las abundantes ilustraciones incluidas en sus páginas, cuyo fin era captar la mirada y el interés de los niños (Antuñano: 26; Brown: 66), incluso podría decirse que los folletines de la "Biblioteca" prefiguran al ulterior género de la historieta didáctica.

Mediante el recurso de la apelación directa a su público, al que llama de continuo "amiguitos míos" o "lectorcitos amigos" (Antuñano: 27), y en un estilo fluido, aunque profusamente adjetivado (muy al gusto del tardío Romanticismo mexicano) (Brown: 66), ${ }^{12}$ Frías desarrolla en sus folletines una visión de la historia patria simplista, maniquea, liberal y absolutamente pro-indigenista. Las nociones de libertad e igualdad se destacan en los acontecimientos históricos que se prestan a ello, como la conspiración del marqués del Valle, la lucha independentista, la Reforma, etc. En contrapartida, la Conquista, el régimen virreinal, los privilegios eclesiásticos y el partido conservador son objeto de sus críticas más acerbas. Se traslucen sentimientos compasivos por los indígenas y una franca admiración por la bravura del pueblo mexicano; a algunos protagonistas de la historia reciente les dispensa lisonjas, entre ellos, a Porfirio Díaz, a quien le atribuye el mérito de haber traído la paz a la nación (Brown: 66; Antuñano: 28).

Desfilan progresivamente en sus folletines los antiguos señores indígenas: Acamapitzin, Nezahualcóyotl y Moctezuma, meritorios por su grandeza; luego dos insignes héroes que enfrentaron a los dominadores españoles: Xicoténcatl en Tlaxcala y Cuauhtémoc en México Tenochtitlan. Los sigue fray Bartolomé de las Casas, proverbial protector de los indios; la conjura del marqués del Valle le da pretexto al autor para hacer un reconocimiento a los primeros "patriotas" que buscaron "liberar" a México de la "barbarie" del sistema colonial. Todos son el preámbulo

\footnotetext{
${ }^{11}$ De acuerdo con Brown la Biblioteca del Niño Mexicano comparte características con dos obras de Frías, Episodios militares y Leyendas históricas mexicanas.

${ }^{12}$ Según Brown este rasgo "es casi paralizante".
} 
a la presentación del egregio cura Hidalgo, iniciador de la lucha libertaria y padre de la nación. Del heroico Morelos se rescata su actuación en el sitio de Cuautla, su genialidad como estratega y su sensatez política. Y en cuanto a Benito Juárez, es ni más ni menos que el líder de la "segunda" independencia nacional (Antuñano: 29).

\section{La Conspiración del marqués del Valle}

Con el número 38, este folletín abre la tercera serie de la "Biblioteca", titulada "Después de la Conquista y el Virreinato". La ilustración de la portada es estremecedora: ofrece la imagen de un verdugo, de pie sobre una tarima de madera y con expresión de enfado; en su mano derecha porta un hacha que hace un movimiento ascendente para descargar el golpe sobre su víctima. Ésta, de hinojos y con las manos atadas a la espalda, viste un elegante atuendo de jubón, gregüescos y calzas, evidentemente se trata de un hombre de posición acomodada. En segundo plano se ven otras dos cabezas cercenadas y sangrientas. Al fondo se esbozan las figuras de un público expectante y boquiabierto que contempla la escena de la ejecución. Así, el grabado presenta al lector el ajusticiamiento de los hermanos Ávila en 1566.

El relato se inicia con el duelo general del reino de la Nueva Espańa en 1564 a causa de la muerte de don Luis de "Velazco" [sic]. ${ }^{13}$ Un virrey que, según el autor, había sido un "padre" para los indios, porque alivió las penalidades de aquellos que servían en las "profundidades oscuras" de las minas. Pero, sobre todo, había sido un gran benefactor de la capital y fundador de la universidad, útil institución educativa donde los jóvenes podían estudiar artes y ciencias para "iluminar la Noche en que antes se encontraban los espíritus".

El vacío de poder dejado por el gobernante muerto en "ese resto de Anáhuac... que se llamaba Nueva España” fue aprovechado por los "hombres viles y ambiciosos" de la Audiencia, con lo que se inició una época "tristísima", llena de iniquidades e injusticias, de crímenes y atropellos. Y luego de esta introducción semihistórica, seminovelada pero de conveniente dramatismo, Frías introduce a dos personajes de ficción,

${ }^{13}$ He respetado la grafía de los nombres, e incluso las erratas del texto original de Frías e indico las inexactitudes con un [sic]. 
el joven Guy y su amada, doña Elsa, que se reúnen de noche y entre "melancólicos árboles" en la ribera del lago de Chalco. Un grabado en blanco y negro representa a la pareja, vestida a la moda francesa del siglo XVIII, al resguardo de un grueso árbol y junto a una barquilla.

El fin de la cita es ultimar detalles para un futuro matrimonio, al que el joven Guy se rehúsa, porque su corazón ya está dado: "primero es de mi patria ¡soy mexicano!", pues resulta que tanto él como su enamorada descienden de "bravos aztecas"; Guy pertenece al linaje de un tal "Netzalma'corgotl" [ $[$ ic $]$ a través de una nieta suya, que iba a morir en "Tecoco" $[$ sic $]$ "por salvar a la patria". Su sangre es pues "una mezcla de español y acolhua". En cuanto a Elsa, es hija de un "caballero español y una princesa azteca". Su compromiso matrimonial fue pactado por sus respectivos padres, antes de que éstos murieran en la hoguera. Elsa había crecido como criada de la marquesa del Valle y su novio como caballero de los condes de Santiago. ${ }^{14}$ Todo indica que Guy avizoraba "algo como un porvenir de independencia para [el] territorio tan hermoso" de su patria y anhelaba liberar de la esclavitud a sus "hermanos los indios", sometidos al poder de una canallesca Audiencia. Por ello, pide a Elsa que interceda ante el marqués del Valle, que es "valiente, un alma alta y digna, capaz de regir el reino mejor" que los aviesos oidores.

Se interrumpe la escena anterior para dar paso a la presentación de un marqués del Valle que, al fin heredero del genio de su "abuelo" [sic] Hernán Cortés, ${ }^{15}$ es "gallardo, poderoso, querido por todos, caballeresco, y muy amante de las glorias de su país". Además, era caritativo y profesaba gran "cariño hacia los desvalidos y humillados". A los méritos de su sangre sumaba los de la esmerada educación recibida en Flandes, donde había "vivido siempre en libertad y en amor a la patria y el respeto a los que piensan y trabajan”. Así que al arribar a México, lo había hecho acompañado de un gran séquito y con el "boato de un rey".

En este momento se gestaba ya un "horroroso drama... de amarguras infinitas, lúgubres desesperaciones y lutos siniestros, empapados en verdaderas lágrimas de dolor, piedad y misericordia" que habría de afectar al marqués y a sus adeptos, pues las palabras como las que había proferido Guy contra el mal gobierno podían incriminar a cualquiera. Quien

\footnotetext{
${ }^{14}$ Un título nobiliario que, por cierto, sólo se concedió hasta 1616.

${ }^{15}$ En realidad, era su hijo. El nieto del conquistador fue Fernando Cortés Ramírez de Arellano, tercer marqués del Valle e hijo de Martín Cortés Zúñiga.
} 


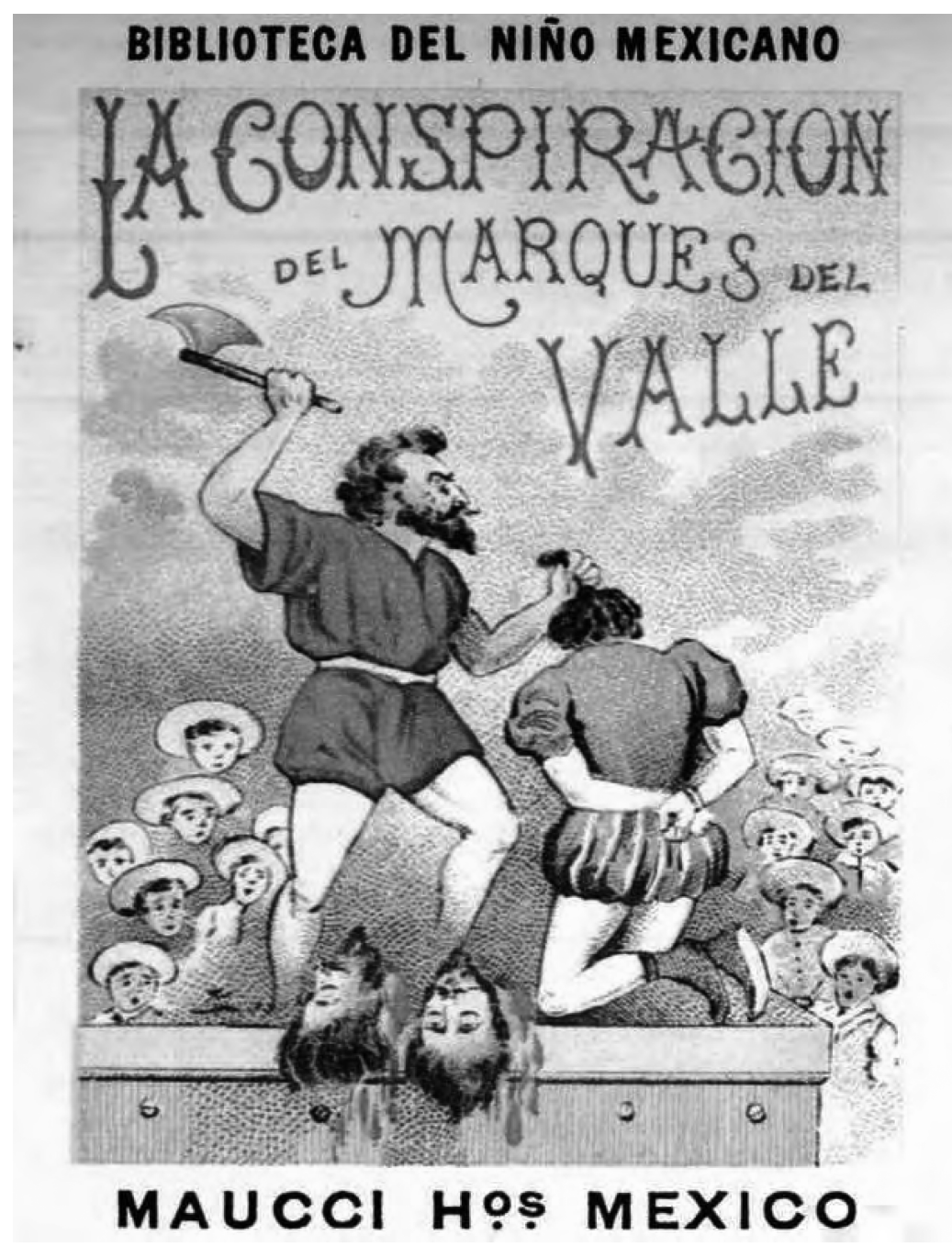

Portada a la edición de Maucci Hermanos, México (1900) 
osara pensar, “con la voz de ¡libertad!", era irremisiblemente condenado a "las rojas llamas de la hoguera de la Santa Inquisición".

A esta digresión sigue el relato de la forzosa separación de los amantes. Elsa se aleja y un grabado muestra cómo es observada por tres hombres ataviados con sombreros de ala ancha - a guisa de los mosqueteros del siglo xvir. Uno de ellos es Guy, quien reflexiona en voz alta: "yo debía luchar y hacer que sólo aquí gobernaran caudillos independientes, no vasallos que se sugetan a otros en nombe $[s i c]$ de un rey lejano que no conocen". Uno de sus acompañantes le pide que guarde silencio si no desea acabar en el cadalso.

Días después de conmemorada la caída de Tenochtitlán -13 de agosto-, se denunció una conspiración contra "el gobierno y el rey" para "coronar como soberano de México, de la que entonces se llamaba Nueva España, al opulento y gallardo Marqués del Valle”. Los acontecimientos se precipitan y los tres personajes, Guy, y los dos hermanos "Alonso y Gil González", "apuestos y caballerosos", han sido prendidos. El último grabado los muestra saliendo del calabozo para dirigirse al patíbulo en la plaza mayor "que ahora se llama de la Constitución y allí fueron decapitadas... aquellas juveniles y hermosas cabezas que acaso alentaban pensamientos nobles hacia la libertad de la patria". Hasta aquí el relato novelado de Heriberto Frías para la "Biblioteca del Niño Mexicano".

Con menos rasgos de heroísmo, pero con un fin igualmente trágico, se revela la historia que ofrecen los documentos y expedientes judiciales del periodo. Martín Cortés, hijo (que no nieto) de Hernán y segundo marqués del Valle, nació en Cuernavaca en 1532 y efectivamente se educó en la metrópoli, donde formó parte del séquito personal de Felipe II. De vuelta en México en 1563 fue objeto de una apoteósica recepción por parte de las elites criollas. Sin embargo, su soberbia, su prepotencia y su conducta irrespetuosa ante las jerarquías pronto lo malquistaron con los poderosos, en especial con el virrey Luis de Velasco. Su llegada a Nueva España coincidió también con la de una cédula real que ordenaba la supresión de encomiendas en "tercera vida", que no era sino una ratificación de las Leyes Nuevas de 1542 que anulaban la transmisión del beneficio para los descendientes de conquistadores. La noticia provocó alarma entre los afectados, que se reunieron y alborotaron, pues no estaban dispuestos a perder su "legítima" herencia y patrimonio. El descontento se incrementó en los meses siguientes y los 
encomenderos empezaron a conspirar a fin de "alzarse con la tierra" y coronar al marqués, a quien atribuían el derecho a regirla por haberla conquistado su padre. El grupo, que encabezaban los hermanos Gil y Alonso de Ávila, notificó del proyecto a Martín Cortés, quien se avino a participar, pero sólo si existía la seguridad de que el plan fuera exitoso y secundado por muchos. Los conspiradores se lo garantizaron y llevaron adelante la trama, hasta que fue descubierta por las autoridades que - habiendo fallecido el virrey_ lo eran los oidores de México. La Audiencia inició los procesos y ordenó la detención del marqués y los demás involucrados, como los hermanos Ávila. A éstos se les halló culpables de traicionar al rey y por ello se les sentenció a sufrir el secuestro de bienes y a ser degollados; otros participantes fueron igualmente ejecutados. En función de su alta jerarquía, la pena del marqués fue menos severa: se le condenó al pago de una multa, al destierro perpetuo de las Indias y a la pérdida de la jurisdicción de su marquesado. En suma, la "conspiración" fue sólo un connato de rebelión que atizó el interés de un grupo privilegiado por mantener sus rentas, es decir, la posesión de encomiendas que les suponía la percepción del tributo indígena. La pretendida "coronación" de Martín Cortés era sólo un requisito para alcanzar ese fin y no una aspiración independentista en sí.

Como bien se sabe, en el siglo xix se gestó, perfiló y consolidó al Estado nacional mexicano. En consecuencia, no sorprende que los historiadores que en aquel entonces se ocuparon del asunto de la "conspiración" del segundo marqués tuvieran una mirada sesgada hacia los intereses "patrios" (Orozco: IX-X). En general, su línea interpretativa defiende no sólo la existencia de una conjura bien organizada, sino que, además, ésta era la que daba voz y cauce al ansia libertaria de los primeros espańoles americanos, que acabaron siendo los protomártires de la nación (Ayala: 5-9). ${ }^{16}$ Sin embargo, representar a la "conjuración" como una precursora del ideario autonomista ilustrado de fines del

${ }^{16}$ La conjuración o conspiración del marqués del Valle y los hermanos Ávila es uno de esos acontecimientos que, por su sigiloso desarrollo y su público e infausto desenlace, a lo largo del tiempo ha reclamado la atención de polemistas políticos, de cronistas e historiadores y aún de literatos. Sin embargo, la brevedad obligada de este texto, y porque otros son sus fines, me impide profundizar en los diversos textos que el suceso ha generado. El autor citado ofrece detalladamente las variadas interpretaciones del suceso. Asimismo, véase el texto de Adriana Sandoval sobre tres versiones literarias del suceso en el siglo XIX. 
XVIII, que culmina en la conformación del independiente y moderno Estado mexicano, es incurrir en una interpretación anacrónica y teleológica; es imponer un molde prefabricado a los hechos en función del resultado esperado, que determina anticipadamente la selección de los temas preponderantes y la de las fuentes. Todo se reduce a crear una genealogía o "tradición" que legitime al Estado nacional.

Y éste es el patrón básico al que se ciñó Heriberto Frías en su relato, muy en concordancia con la esquemática concepción histórica de Guillermo Prieto, quien escinde a los personajes del pasado virreinal en sólo dos bandos, el de los malos, i.e. los opresores y retrógrados peninsulares, y el de los buenos: los oprimidos criollos y sus explotados "hermanos" indígenas que aspiraban a la libertad.

Por otro lado, no puede sorprendernos que a la conclusión del siglo XIX y los albores del xx se inculcaran con semejante tesón en los educandos estos gérmenes de nacionalismo. Tratándose de la formación masiva de una futura ciudadanía, no era cuestión de ponerse exigentes con los autores de textos escolares en cuanto a la exactitud de los hechos del pasado, mucho menos en la veracidad de los contextos históricos en los que éstos se dieron; pero sí, en cambio, había que ser muy puntillosos en el sentido general que debían tener los relatos. A los niños había que enajenarlos de un dominador extraño que era súbdito de "un rey lejano"; insistirles en el reconocimiento y la orgullosa jactancia de su origen mestizo, mezcla de "brava" sangre "azteca" y española, y convencerlos de la presencia constante de anhelos de independencia o "mexicanidad" en sus ancestros más remotos. Todos estos requisitos se cumplen a pie juntillas en "La Conspiración del marqués del Valle" de la "Biblioteca del Niño Mexicano".

Finalmente, no puede dudarse del buen éxito obtenido a la larga por la literatura histórico-pedagógica producida en ese momento (y en dos buenas terceras partes del siglo $\mathrm{xx}$ ). El prejuicio antihispánico todavía está presente y vivo entre gran parte de la población mexicana: los clichés de "explotadores" y "expoliadores de riqueza" que acompañan a toda referencia a los conquistadores, la persistencia de la Leyenda Negra, la fama siniestra del Santo Oficio y otros lugares comunes que la gente repite como si se tratara de hechos irrefutables así lo corroboran.

Y en lo que corresponde a la "Biblioteca del Niño Mexicano" cabe señalar que también sentó un precedente. En fechas recientes y con motivo de la celebración del Bicentenario de la Independencia, se produ- 
jeron 50 audiolibros de una serie titulada "Nueva Biblioteca del Niño Mexicano", bajo los auspicios de la Coordinación Ejecutiva para las Conmemoraciones de 2010, Conaculta y el Fondo de Cultura Económica, aunque sólo dirigidos a presentar la historia de la guerra de Independencia y la de la Revolución mexicana.

Pero tal puesta al día de la idea original de Heriberto Frías no ha cancelado ni anulado el uso de sus centenarios folletines de divulgación: en el ciberespacio puede consultarse hoy en día una página (Turismo mexiquense 2012) que recoge la "vida" de Nezahualcóyotl, "el rey justo", que imaginara el autor queretano y la presenta a los lectores como si de una historia cabal se tratase.

\section{BibliografíA}

Antuñano Maurer, Alejandro de. "Estudio preliminar", en Heriberto Frías. En torno a la Biblioteca del Niño Mexicano. 2a edición facsimilar. México: Miguel Ángel Porrúa Librero-editor, 1987.

Ayala Tafoya, Eduardo. La "conjuración" de Martín Cortés: un ensayo sobre la cultura política de la Corona y de los criollos novohispanos. Tesis de maestría en Historia. México: Facultad de Filosofía y Letras. Universidad Nacional Autónoma de México, 2015.

Bazant, Mílada. Debate pedagógico durante el porfiriato. México: Secretaría de Educación Pública / Ediciones El Caballito, 1985.

Bazant, Mílada. Historia de la educación durante el porfiriato. México: El Colegio de México, 2006.

Brown, JAmes. The Life and Works of Heriberto Frias. Bloomington: Tesis doctoral. Departamento de español y portugués. Universidad de Indiana, 1967.

Cortázar, Alejandro. Reforma, novela y nación. México en el siglo xix. Puebla: Benemérita Universidad Autónoma de Puebla / Dirección de Fomento Editorial, 2006.

Escandón, Patricia. "La historia antigua de México en los textos escolares del siglo xix", en Secuencia. México, 10, 033 (1988): 33-42.

Fernández Delgado, Miguel Ángel. Ignacio Manuel Altamirano: la pluma y la espada de la República. México: Suprema Corte de Justicia de la Nación, 2006.

Frías, Heriberto. ¿Águila o sol? México: Editorial Offset, 1984.

García Gutiérrez Vélez, Georgina. "Estudio preliminar", en Heriberto Frías, La escritura enjuiciada, una antología general. Selección, edición, 
cronología y estudio preliminar de Georgina García Gutiérrez Vélez. México: Fondo de Cultura Económica / Fundación para las Letras Mexicanas / Universidad Nacional Autónoma de México, 2008 (Biblioteca Americana. Serie Viajes al Siglo XIX).

López Peimbert, David. Tomóchic. Tesis de maestría en Letras. México: Facultad de Filosofía y Letras. Universidad Nacional Autónoma de México, 1963.

Martin, Leona. "Entre La antología de poetas hispanoamericanos de Marcelino Menéndez Pelayo y Los parnasos de la Editorial Maucci: Reflejos del ocaso de la hegemonía colonial" (2006). Artículo en línea disponible en: <http://www.lehman.cuny.edu/ciberletras/v15/martin.html>.

Orozco y Berra, Manuel. Noticia histórica de la conjuración del Marqués del Valle. Años de 1565-1568. México: Tipografía de R. Rafael, 1853.

Ortega y Medina, Juan A. Polémicas y ensayos mexicanos en torno a la historia. 3a ed. México: Universidad Nacional Autónoma de México, 2001.

Pi-Suñer Llorens, Antonia (coord.). Historiografía Mexicana. Vol. 4. En busca de un discurso integrador de la nación, 1848-1884. México: Instituto de Investigaciones Históricas. Universidad Nacional Autónoma de México, 1996.

Prieto, Guillermo. Lecciones de historia patria. México: Tipografía de la Sría. de Fomento, 1886.

RÉbSAMEN, EnRiQue. Guía metodológica para la enseñanza de la historia en las escuelas elementales primarias y superiores de la república. Jalapa: Imprenta del Gobierno del Estado, 1891.

Saborit, Antonio. Los doblados de Tomóchic. Un episodio de historia y literatura. México: Cal y Arena, 1994.

SAndoval, Adriana. "Tres versiones literarias de una conspiración”, en Literatura Mexicana. México: Centro de Estudios Literarios. Instituto de Investigaciones Filológicas. Universidad Nacional Autónoma de México. XXVI-1 (2015): 41-64.

Turismo Mexiquense. "Historia. Nezahualcóyotl, el rey justo" (2012). Artículo en línea disponible en: <http://turismomexiquense.blogspot. $\mathrm{mx} / 2012 / 10 /$ historia-nezahualcoyotl-el-rey-justo.html>.

VÁzQuez, Josefina. Nacionalismo y educación. 2a ed. México: El Colegio de México, 2000. 